\title{
AN OPTIMISED WORKFLOW FOR THE INTERACTIVE EXPERIENCE WITH CULTURAL HERITAGE THROUGH REALITY-BASED 3D MODELS: CASES STUDY IN ARCHAEOLOGICAL AND URBAN COMPLEXES
}

\author{
L. Cipriani ${ }^{1}$, S. Bertacchi ${ }^{1}$, G. Bertacchi ${ }^{1, *}$ \\ ${ }^{1}$ Department of Architecture, Alma Mater Studiorum - University of Bologna, Italy - (luca.cipriani, silvia.bertacchi, \\ gianna.bertacchi2)@unibo.it
}

KEY WORDS: Cultural Heritage, reality-based 3D models, digitisation, procedural modelling, game-engines, visualisation

\begin{abstract}
:
The paper compares two workflows for the achievement of 3D models aimed at in-depth studies on the geometric features of Cultural Heritage artefacts and their dissemination. The purpose is the outlining of pros and cons of different techniques coming from entertainment and video games industry, starting from highly reliable 3D documentation of cultural assets, i.e. architectural/archaeological/urban sites. Two different possible applications are described: (i) procedural modelling used for understanding and visualising reconstruction hypotheses of the vaulted pavilions at Hadrian's Villa, Tivoli, Rome; (ii) optimisation of 3D high-detailed models, as input files, turned into visual reliable and highly portable assets for game-engines. The first case study is focussed on creating a flexible model for evalueting reconstruction hypotheses and supplying restorers with useful hints for shape completion of ruined pavilions. The second case study makes available detailed digital contents for storytelling historical and cultural events in an attractive way, as in the case of the urban explorative model of Chiuro, a small town in northern Italy.
\end{abstract}

\section{INTRODUCTION}

There are continuous and substantial developments in the research landscape on digitisation related to the documentation and enhancement of Cultural Heritage. Nowadays numerous devices, software and platforms are available for specific needs with particular tools to acquire, process, model and manage 3D assets: accuracy, usability, practicality and effectiveness are some of the requirements taken into consideration by users, together with low-cost, rapid solutions and instruments.

For years now, digital documentation activities for $\mathrm{CH}$ are mainly based on accurate 3D reality-based models - both Terrestrial Laser Scanner (TLS) and photogrammetry-based -, especially when information on shape and colour is a basic requirement, aided by the fact that these methodologies and techniques have spread swiftly in the scientific community becoming increasingly affordable, reliable and ease to use, with manageable tools to integrate different sensors, decreasing costs and time (Ioannides et al., 2018; Remondino et al., 2018).

Apart from standard solutions for documentation using digital models as reliable resources to communicate and share contents, the current trend is now turning towards novel and more powerful ways to enjoy $\mathrm{CH}$ three-dimensional contents and related information by means of different approaches, provided in response to major issues and addressing particular users (García-León et al., 2018). For instance, (i) to have smart and easy management of huge amounts of articulated and heterogeneous data over time (structured information systems and web-platforms for public administrations and professionals), (ii) to have flexible control over shape generation (parametric, procedural or generative 3D modelling for 3D experts), (iii) to have an intuitive and effective dissemination with the general public (interactive and immersive experiences for non-experts of digital reconstructed $\mathrm{CH})$.

Among the various experimentations carried out at present by researchers on these challenging issues, we developed our workflow starting from 3D reality-based models for $\mathrm{CH}$ experiencing in two different ways: on the one hand to find a high-performing and flexible system to deal with complex architecture reconstruction hypotheses, easy to handle for reflecting changes in case of revisions requested during the study by the interdisciplinary team; on the other hand to visualise and give access to detailed digital contents through game-engines for storytelling historical and cultural contents in an attractive way.

The researches presented in this paper focuses on the definition of a workflow for the documentation of peculiar cultural assets, characterised by a physical complexity in terms of both spatial extension and data integration in order to develop an optimised model, with defined accuracy and geometric resolution, avoiding the burdensome and time-consuming manual postproduction operations generally applied to scanner/photogrammetric models (Merlo and Fantini, 2012; Merlo et al., 2013).

The paper is organised as follows: Section 1.1 reviews briefly major trends and some related works in the research field, focussing on our proposed workflow (Section 2); Sections 3 and 4 detail our workflow tested on two different case studies; Section 5 draws some conclusions on the topic.

\subsection{Current interests in $\mathrm{CH}$ digitisation}

Digitisation techniques have become customary in the $\mathrm{CH}$ domain, and 3D modelling from reality has achieved fully satisfactory results relating to geometric and aesthetic accuracy.

\footnotetext{
* Corresponding author
} 
Significant progress is recorded in standard procedures and devices for capturing high resolution models of architectural and archaeological artefacts, including mobile devices, UAV and smartphone-based 3D reconstruction (Muratov et al., 2016; Nocerino et al., 2017a; Nocerino et al., 2017b). There are continuous and substantial developments in the research landscape on rapid digitisation related to the documentation of Cultural Heritage. Nowadays these methodologies are able to integrate different sensors and to allow an immediate use of digital images as systems open to dialogue with database and applications, for the interactive experience of digital buildings, urban contexts and landscapes (Gaiani et al., 2015). Moreover, many experiments are carried out also to find low budget acceptable solutions for rapid documentation but mostly focussed on virtually-aided visualisation than on metric accuracy (Napolitano et al., 2018).

Nevertheless, research over these years has demonstrated the urgent need to go further as regards the interpretation of gathered data. Digital models in fact, beyond the mere shape acquisition and metric information, are turning into repository of knowledge and users increasingly need tools for managing and exploiting resources effectively. Enhanced interest in this sector is demonstrated by numerous studies on Information Systems and web-platforms (Scopigno and Dellepiane, 2017), specifically created for heritage scientists for i.a. improving analytic and diagnostic activities and creating specific tools for restorers, to study, visualise and add information directly on the high-resolution 3D model, even on-site. A major benefit indeed is the multidisciplinary approach provided and user-friendly and operational tools for non-experts.

Within this framework, an extensive and diversified range of solutions are now been developed following $\mathrm{CH}$ operator requirements and Informative Systems can be an answer to the need of integrating data in a platform accessible in multiuser mode, that is based upon a 3D high detailed model of the cultural asset and that allow to manage all the aspects during the whole data lifecycle of the $\mathrm{CH}$. In the more recent projects, mention should be made of our team's contribution to the topic as shown in Apollonio et al. $(2017,2018)$ and Bertacchi et al. (2018).

Another relatively recent emerging technology in the Architecture, Engineering and Construction (AEC) sector for $3 \mathrm{D}$ modelling and virtual reconstruction is the Building Information Modeling (BIM) standard. Nowadays, the increasing attention to H-BIM (Heritage-BIM) is fostered by implementations and progresses that allowed its adoption also in the Cultural Heritage domain, thanks to integration of realitybased data captured with sensors, interaction with different kinds of data for various analysis, interpretation and management of more complex architectural shapes. Some interesting review on the topic can be found in the up-to-date scientific literature (Quattrini et al., 2015; Logothetis et al., 2015; Biagini et al., 2016; Banfi, 2017; López et al., 2018; Chiabrando et al., 2018).

However, although parametric model can be congruent with metric survey information and many tests have been performed on the point transformation into 3D models linked to databases (Dore and Murphy, 2017; Pocobelli et al., 2018), the use of high-quality polygonal models, especially if mapped with ad hoc referenced maps - like UV mapping that is a standard in the computer graphics field -, is much less widespread inside BIM applications and remains a major difficulty, besides the expertise necessary to model families of elements of interest as intelligent objects with semantic attributes.

Over the last decades, in addition, there have been significant developments in the use of virtual reality (VR) devices and game-engines for the visualisation of 3D models as means of spreading cultural awareness of historical events and heritage assets (Gonizzi Barsanti et al., 2015).

Immersive VR application in fact are proved to be a smart system of discovery and a way of motivating people to virtually deepen knowledge of cultural objects or to learn about new cultural places to visit (Fernández-Palacios et al., 2017; GarcíaLeón et al., 2018).

\section{PROPOSED WORKFLOW}

On this basis, our team has for years been pursuing the objective to generate high-detailed reality-based 3D models, directing its efforts to develop customised workflows for (i) 3D acquisition based on TLS and/or close-range photogrammetry, (ii) reliability of colour (Gaiani et al., 2017) and (iii) enhanced visualisation of outcomes to fully accomplish and exploit the visual potential of models (Cipriani and Fantini, 2018). As a matter of fact, our main purpose is having at disposal a high level of detail for documentation and knowledge to carry out geometrical analysis required by restorers and archaeologists (Adembri et al., 2018a; Adembri et al., 2018b) and to foster knowledge exchange and share virtually reconstructed heritage scenarios to be manageable and easily understood also by nonexperts. To do this, since some very specific demands require individual solutions, some previous experiences with multidisciplinary working groups have contributed to moving towards optimised solutions both in procedural modelling and retopology solutions, leaving aside for the moment scan-to-BIM approaches.

The main issue in this procedure is how to combine the huge amount of raw available data with their geometrical detail and the model effectiveness, often acquired at different times, with various tools and methodologies. Hence, the research focusses on the definition of optimisation workflows for specific complex cultural assets in order to obtain flexible models, with optimal visual appearance and geometrical reliability, but manageable and without affecting the quality of the 3D model.

Two different case studies starting from the same "raw" data at disposal but with different purpose have been considered as representative to test these two solutions: (a) the procedural modelling of some vaulted pavilions of Hadrian's Villa in Tivoli (Rome), an articulated archaeological complex repeatedly subject matter of a sequence of digital surveys, operated by different teams, at different times and with various methodologies; (b) the digitisation of the historic centre of Chiuro (in northern Italy, Sondrio), a traditional urban site, whose documentation is aimed at the visualisation and exploration of the town within game-engines (Cipriani et al., 2018).

In the following sections, some partial results of these two ongoing research will be show.

The proposed workflow is summarised in Figure 1.

The two pipelines start both from reality acquisition (through photogrammetric and laser scanner survey) achieving the master model, that is the high-detailed version of the digital capture. Then they differ in the subsequent processing according to the final goal: on one side (case A - Roman vaults), there is the creation of a model aimed at the heuristic achievement of the geometrical features and hypothetical reconstruction of partially preserved architecture that is dynamic; on the other side (case B - Urban interactive visualisation), a series of steps lead to a photo-realistic interactive digital asset that is static since it represents an "as-built" scenario.

Detailing the two options for processing the achieved 3D master model, case A is a less automatic modelling method due to the 
fact that reconstruction hypotheses are based on collaborative interdisciplinary research, therefore a continued collaboration with archaeologists, restorers and other professionals involved in restoration and maintenance process is necessary. For this kind of study, high-detail models are sliced in order to get simple primitives (lines, arc of a circle) and a series of contour lines that show morphologically salient elements of a building. Indeed, only heritage scientists have the expertise to point out the presence of relevant architectural elements and traces where to position interactive planes in the three-dimensional environment to achieve reference sections that can prove useful in the reconstruction procedure.

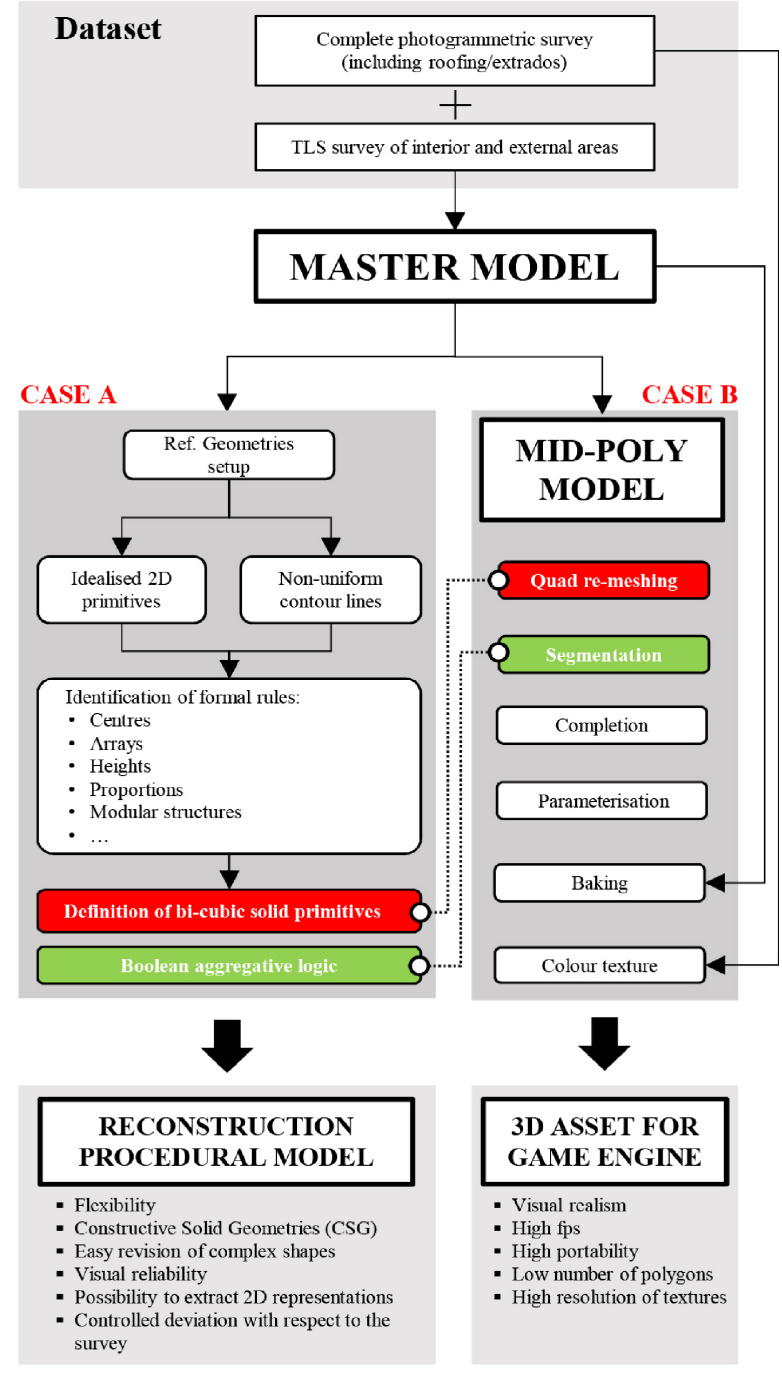

Figure 1. Outlined workflow.

The first step is to find where to locate slicing planes in order to identify features: these curves will be used for a series of operations starting in general from the plan of the building. So, thanks to reverse modelling tools, an idealised and simplified plan of the building is redrawn.

Elements of interest for the understanding of a building's original shape are randomly scattered upon the architectural surface: original elements of the floor, decoration, intrados and extrados appear here and there without a unique logic. They can be identified by means of a careful observation or noticed after restoration and maintenance practice. For instance, in relation to extrados surfaces, it is quite common to achieve a better knowledge of the original aspect of the cupola as the result of constructive material removal. Restoration cover made of mortar forming a protective layer, in many cases, hide the original shape of the building and cannot be detected through a common surveying campaign (documenting only the external surface of the artefact).

Moreover, for centric-designed spaces, it is necessary to draw the plan in order to find the average centre of the indoor environment and consequently the centre of the vault or cupola. This element is a major one for the construction of a procedural model, because it organises through a radial array the series of circular and rectangular niches forming the mixtilinear pattern of the building. The advantage of a procedural approach is relevant once the model is compared to non-uniform contour lines, obtained by means of reverse modelling applications (Cipriani et al., 2014a).

Another major aspect of procedural modelling, facilitating creation of common formal rules linking plan and elevation, is the presence - in the general layout of Roman buildings - of grid-based design. Modules can manage the dimensioning of the main elements of a building through a standard procedural modelling pipeline. In fact, a modular structure allows the user to define all the elements of the construction by referring to a specific quantity multiplied by a scalar number or a mathematic function. Plans and elevations of Roman centric plan designs are usually characterised by simple ratios (1:1); for this reason, it is possible to define the majority of the elements of a building starting from a limited number of measurements.

Once 2D templates (generatrix, directrix, etc.) are determined, a first division of the building into a series of simple shapes is carried out. This phase has the aim to achieve a series of simple geometric shapes formed by bi-cubic surfaces. The reason for this choice is due to the recent implementation of Boolean operators inside a procedural modelling framework in some applications. These bi-cubic Catmull-Clark shapes are formed by "quads" (Catmull-Clark, 1978; De Rose et al., 1998), namely a complex of rectangular polygons then converted into subdivision surfaces. This strategy was proven to be quite effective in case of highly deteriorated masonry, especially opus caementicium vaults and cupolas since it can be converted into a light, easy deformable, smooth surface, starting from a draft control polyhedron. Due to the difficult understanding of the original shape of these vaults, as well as the exact amount of mortar laid upon opus mixtum and pozzolanic concreate, a procedural bi-cubic surface allows an easy revision of the reconstructive model whenever necessary.

In case B, it is advisable to use a lighter model (mid-poly), rather than a highly detailed one, for carrying out more easily further processing phases (Cipriani et al., 2014b). In fact, master models achieved in the common step usually cannot be used on common PC and need highly performing workstations and specialised high-end applications of reverse modelling and mesh processing. For this reason, in case of specifically-tailored game-engine models, a first decimation process is necessary, to create an intermediate version lowered in resolution, topologically "healed", whose aim is to form the base for a more robust decimation process through a quad-dominant remeshing algorithm; this step facilitates further operations to be carried out inside entertainment applications that, at the moment, can only manage an intermediate amount of polygons (ranging from 500.000 to 5.000 .000 faces). Then the mesh model is split into a subset of polygons, each one characterised by a series of common features (semantic enrichment).

It should be noted that in both cases (in case A manually, automatically in B), the shape is reduced to a lower number of information sharing some aspects: vector primitives, as well as belts or loops of quadrangular polygons, are aligned to curvature lines (Jakob et. al, 2015). 
Another common aspect is that in several cases these curves and sequences of connected edges have a similar arrangement with semantic hierarchy of the analysed building, e.g. the sequences of edges defining the seams or borders present between two constructive elements.

\section{HADRIAN'S VILLA VAULTED PAVILIONS}

Hadrian's Villa, the Roman emperor residence in Tivoli, near Rome (2nd century AD), is a unique combination of very peculiar buildings, erected with the latest innovation in Roman construction, as the concrete technique experimented with audacity in the domes (Opper, 2008). What we can see now are mostly ruined buildings, after centuries of exposure to atmospheric agents, spoliations and restoration works, but that still preserve such particular examples of partially preserved vaulted pavilions. Various in-depth studies have been carried out with the aid of high-resolution models in order to outline reconstruction hypotheses: 3D digital models appear to be necessary for dealing with these complex structures (for instance, because of their considerable height, often exceeding ten metres).
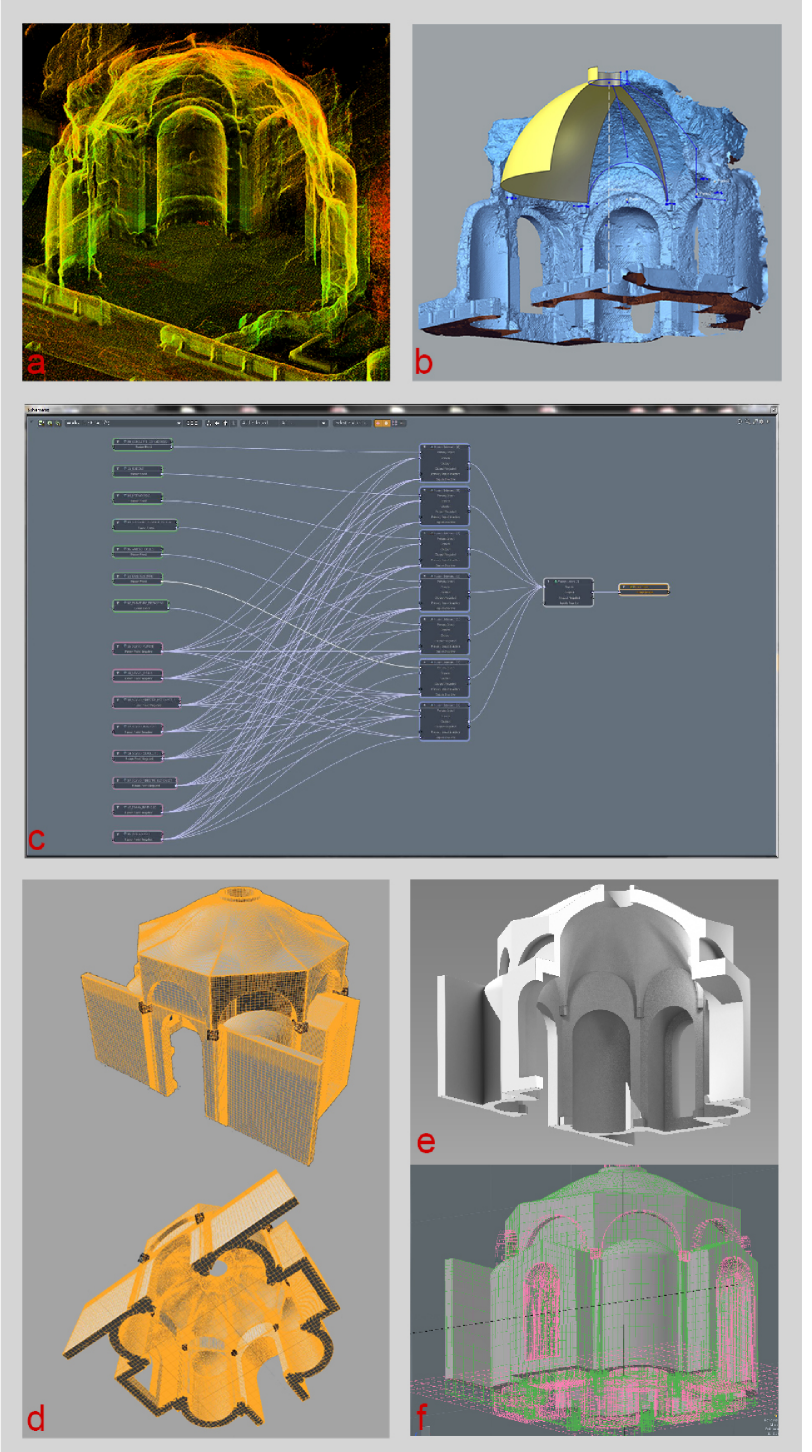

Figure 2. Case A workflow applied to the Vestibule of the Water Court (Vestibolo di Piazza d'Oro), Hadrian's Villa.

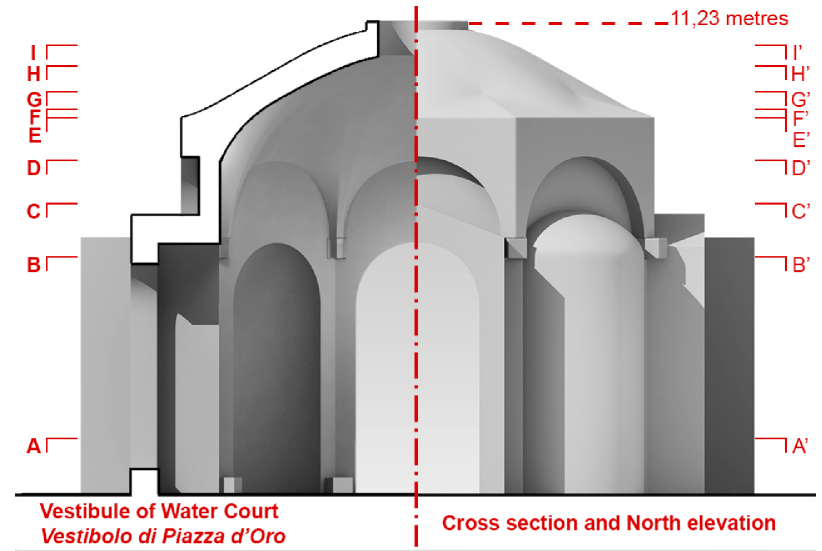

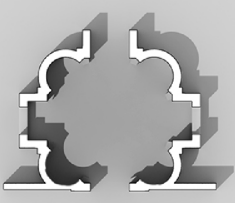

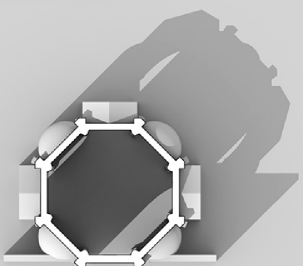

CC'

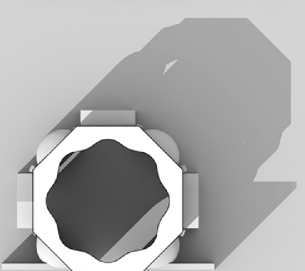

EE'

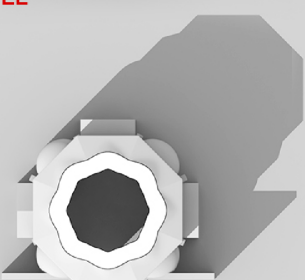

GG

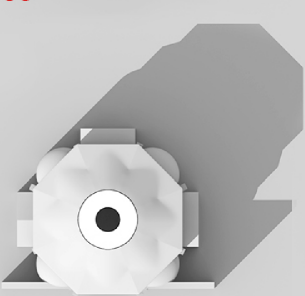

II'

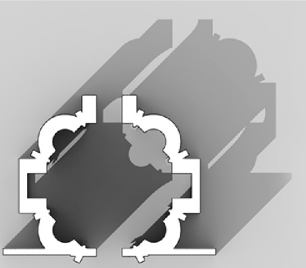

BB'

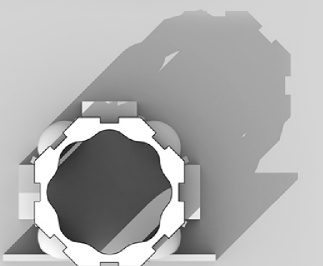

DD'

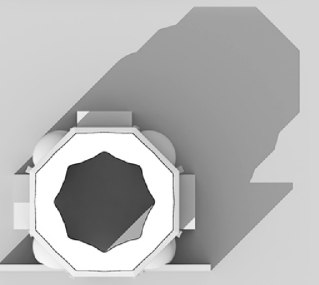

FF'

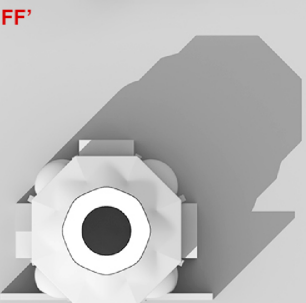

$\mathrm{HH}^{\prime}$

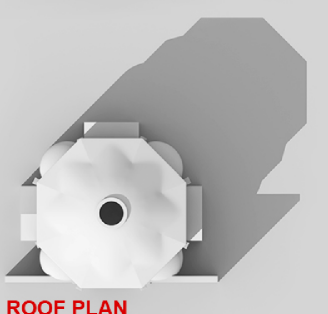

Figure 3. Vestibule of the Water Court. Rendering images of subsequent horizontal sections of the $3 \mathrm{D}$ procedural model of the Vestibule.

Over the last few decades, the Villa has been the target of many survey campaigns: different teams of archaeologists, architects, 
engineers and historians have gained data applying different methodologies and instruments.

In addition, in-depth studies carried out by our research team focused on the principal vaulted pavilions of Hadrian's Villa, e.g. Vestibule of the Water Court, Octagonal Hall of Small Baths, Heliocaminus Hall, Serapeum complex (Cipriani et al., 2016; Cipriani et al., 2017).

In this framework, an initial demanding task is how to combine the model effectiveness and the huge amount of raw data, often acquired at different times, with several tools and methodologies. Then, the aim is how to transfer the essential information from the reality-based model to the reconstructive model, in order to obtain one or more versions for research purposes. In fact, one of the key strengths of procedural modelling is the ease of introducing variations without starting from scratch each time and providing an immediate response to people involved during the study phase (i.e. different professionals with different background).

Our customised workflow to create the procedural model of the reconstruction hypothesis has been applied to the Vestibule of the Water Court, with the following steps: (1) achievement of the master model by processing the TLS survey point clouds (Figure 2a); (2) setup of salient geometry through extrapolation of $2 \mathrm{D}$ primitives and non-uniform contour lines from the master model; (3) identification of formal rules for modelling; (4) definition of bi-cubic solid primitives and boolean aggregative logic. Steps 2-4 are carried out with the software Foundry Modo 12.0v1 (MODO, 2019). The scheme of operators applied to primitive curves to obtain the reconstruction model is illustrated respectively in figure $2 \mathrm{~b}-\mathrm{c}$ and $2 \mathrm{~d}-\mathrm{f}$.

Finally, we can consider the model as the result of modelling operations and relations between surfaces derived from the primitive geometric elements. This is very useful in this specific case study, in fact, the geometric pattern followed during the original project is based upon a radial array, so the change upon a slice of the whole structure will affect the entire model, easily providing different geometric reconstructions.

The final output of the procedural modelling technique is the 3D model shown in figure 3 with some planar sections for preliminary geometric analysis of the vaulted space.

\section{EXPLORATIVE MODEL OF CHIURO}

The digital acquisition of Chiuro (SO), located in northern Italy, is part of an ongoing project for the documentation of the original urban structure of the small town, whose interesting remains of Mediaeval towers and Renaissance palaces are still well preserved.

Three survey campaigns were carried out during the two-year period 2016-2018 using TLS sensor (Leica ScanStation C5) for documenting metric information of several streets and some significant historic buildings of the central area, capturing more than 180 scans (Figure 4). Moreover, close-range photogrammetry has interested the same area to achieve surface colour information; the campaign with a telescopic shooting system (3D-eye) has permitted to acquire also the upper part of the building and elevations, otherwise difficult to shoot, because of the narrowness of the streets.

Starting from this large amount of 3D models, the challenge for this case study was to convert available information into an interactive visualisation in a game-engine, keeping a high quality and frame rate (Merlo et al., 2012).

The use of game-engines provides a useful tool for dissemination and cultural consciousness on $\mathrm{CH}$; some key strengths are: (i) immersive experience in the $\mathrm{CH}$ reconstruction can stimulate curiosity and enhance the notoriety of minor places to improve tourism and dissemination of small realities; (ii) game-engine environments can be used as sets for movies, games and documentary, providing a high-quality product; (iii) exploration fluency provide a light but well represented tool for web visualisation.
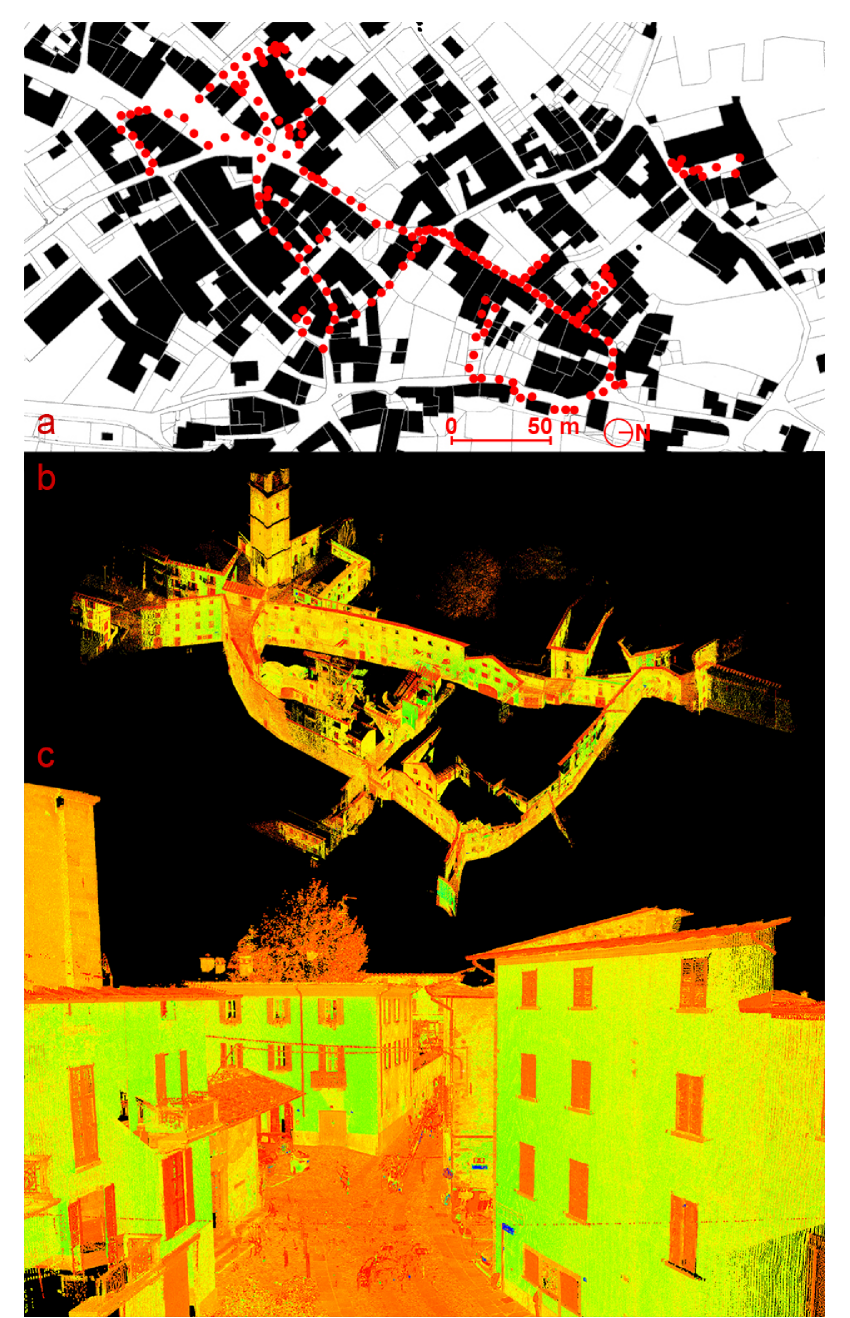

Figure 4. (a) Map of Chiuro with scan locations. (b-c) Views of some registered scans.

The proposed workflow has been applied to the sixteenthcentury gate situated in the main square of the town (Figure 5). The mid-poly model, obtained by the master model mesh, has been optimised with a quad-remeshing procedure: starting from the triangular mesh, this automatic retopology procedure creates a surface composed by quads (Figure $5 \mathrm{c}-\mathrm{e}$ ) that makes it easier to achieve the semantic partition (Figure $5 \mathrm{f}$ ). Texturing on the high-resolution mesh has been performed by means of Agisoft PhotoScan Professional (PhotoScan, 2019); normal maps of each model have been created by normal baking the high-poly mesh in Foundry Modo 12.0v1. Then the 3D model with related textures and normal maps have been imported in the gameengine Unreal Engine (Unreal, 2019) to build the scene. Normal maps and textures already presented UV mapping, automatically recognised in the software. The scene has been created using a low-poly model of the streets and the buildings, and a medium-poly of some particular areas of interest, i.e. the gate of the main square. The scene illumination has been set up using a sky sphere, a sky light, a directional light and some spot lights. The total polygons present in the scene are about 4,8 
million, being the gate composed of 837'006 faces. All textures and normal maps have a 4096x4096 pixel size.

Real-time renders have been tested on a medium-quality laptop with the following specifications: Intel ${ }^{\circledR}$ Core $^{\mathrm{TM}}$ i7-5500U with Intel HD Graphics 5500 (2.4 GHz, $4 \mathrm{MB}$ cache, 2 cores); 16 GB SDRAM DDR3L $1600 \mathrm{MHz}(2$ x 8 GB); NVIDIA GeForce 840M (4 GB DDR3 dedicated). Frames have a 16:9 ratio and a 1920x1080 pixel resolution (Figure 5g-h). Scene simulations have been analysed with Fraps ${ }^{\circledR}$, a software that can show the Frames Per Seconds (FPS) and export statistics (total frames, time, minimum and maximum value, average). The average result on the tested real-time rendering has a value of 74,1 FPS and the minimum value is 55 FPS. These values are compatible to a good smoothness of the video.

Future developments of this ongoing research envisage doing further campaigns for the integration of currently missing urban areas (some of the models still lack the final texture because the acquisition step is still in progress), in order to complete the virtual experience of Chiuro.

\section{CONCLUSIONS}

The paper focusses on customised and optimised workflow to exploit reality-based 3D models of Cultural Heritage, which is illustrated by means of two different case studies, namely the reconstructive hypotheses of ruined vaulted pavilions preserved at the archaeological site of Hadrian's Villa, and the design of an interactive experience for public dissemination in an urban structure, the town of Chiuro. These solutions have different purposes: on the one hand to use procedural modelling starting from available data as a working tool to virtually reconstruct ruined architecture and easily modify the digital outcome after validation of the hypothesis with $\mathrm{CH}$ scientists and experts of the topic; whereas on the other hand to optimise 3D models for promoting $\mathrm{CH}$ contents to the general public by means of gameengine techniques and virtual solutions (in historic centres).

Dissemination and study on the material and immaterial aspects of complex stratifications, such as those present in historical centres and archaeological sites, require a flexible approach, open to multiple software and hardware solutions and independent from the software producers, that in many cases alter optimal workflows for commercial reasons. Cultural assets, particularly those with an archaeological nature, cannot be simplified through simplifications in contrast with the constructive and aesthetic qualities that have determined their "fortune" over the centuries. In the scope of historical centres, wall stratification, colour, variable forms in which the degradation compromises and alters the superficial aspect of these artefacts are the essential aspects that allow the user, even virtual, to have a complete and conscious experience.

Both these characteristics, aesthetic qualities intrinsic to the shape and suggestion of the passage of time that characterises a space, are very far from the technicality and the need to find allinclusive software solutions within a unique application. On the contrary, a wider set of different software enables a richer and fulfilling level of quality of virtual simulacra. The main elements of unification between models, underlined in this paper, are the geometric and formal criteria underlying the construction: the consistency of their components (edges, polygons) with buildings formal and constructing features. In particular, "quads" lead to a more reliable representation of the intrinsic characteristics of the form they are supposed to represent, facilitating the dialogue among applications and future updates.

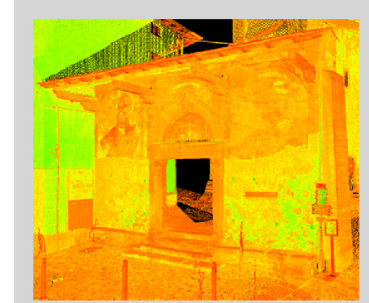

a

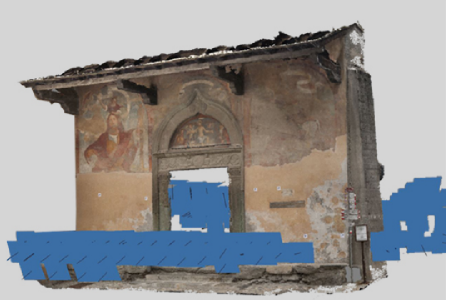

b

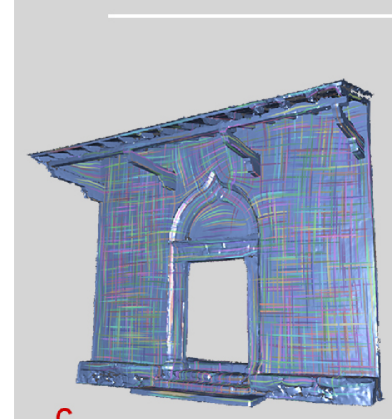

C

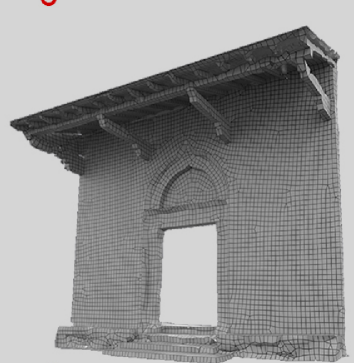

e

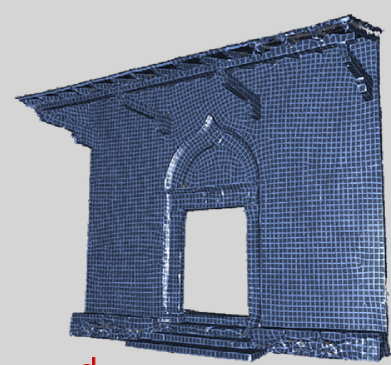

d

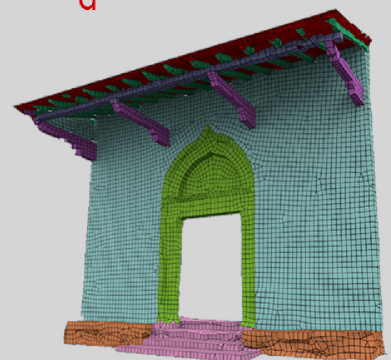

f

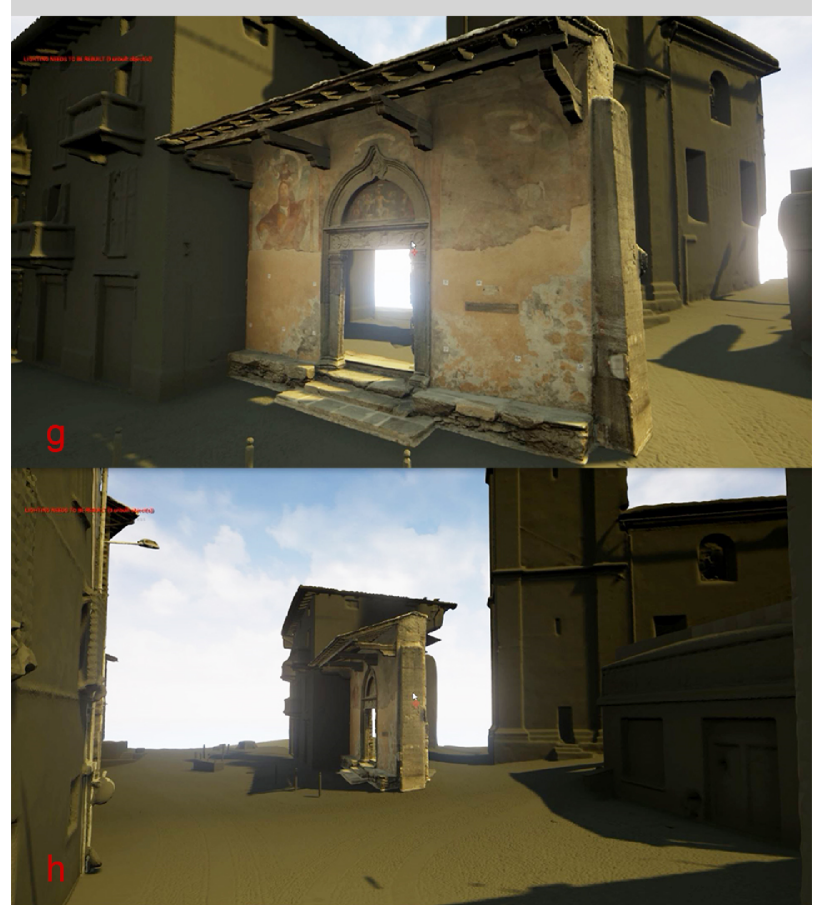

Figure 5. The sixteenth gate situated in the main square of Chiuro: (a) Point cloud; (b) Photogrammetric model; (c-d) Remeshing procedure in InstantMeshes (GitHub); (e) Quaddominant isotropic mesh; (f) Semantic partition; (g-h) Frames derived from a walkthrough in the game-engine scene. 


\section{ACKNOWLEDGEMENTS}

Authors would like to thank experts, colleagues, graduates and students involved in the case studies. In particular: Hadrian's Villa: PhD B. Adembri for scientific advice on vaulted pavilions; Prof. F. Fantini for technical advice on modelling; students of the University of Bologna participants to surveying workshops; Prof. P. Caliari and students of the Master in Architecture and Museum Design for Archaeology - Innovative Design and Management of Archaeological Heritage participating to surveying campaigns; Chiuro: the Municipality of Chiuro for the ongoing collaboration project on Il centro storico di Chiuro: Un laboratorio di architettura founded within the framework Le radici di una identità - Emblematici maggiori 2017 by Fondazione Cariplo; Luca Dalcò and LKA game development studio (http://www.lka.it/); Andrea Dresseno for including Chiuro inside the narrative Italian Videogame Program (IVIPRO) database (https://ivipro.it/en/home-en/); students and graduates of the University of Bologna participants to surveying workshops.

\section{REFERENCES}

Adembri, B., Cipriani, L., Bertacchi, G., 2018a. Virtual anastylosis applied to the architectural decoration of mixtilinear buildings in Villa Adriana: the case study of the scattered friezes of the Teatro Marittimo. Applied Geomatics, 10(4), 279293. doi.org/10.1007/s12518-018-0207-5.

Adembri, B., Juan-Vidal, F., Cipriani, L., Fantini, F., Bertacchi, G., 2018b. Edificios y decoraciones arquitectónicas de tipo mixtilíneo en Villa Adriana: documentación, análisis y restitución virtual de fragmentos dispersos. Marcos-Alba, C.L., Juan-Gutiérrez, P.J., Domingo-Gresa, J., Oliva-Meyer, J. (eds), EGA 2018, XVII Congreso Internacional de Expresion Grafica Arquitectonica. De trazos, huellas e improntas. Arquitectura, ideación, representación y diffusion. Universidad de Alicante, Alicante, ES, 435-444.

Apollonio, F.I., Basilissi, V., Callieri, M., Dellepiane, M., Gaiani, M., Ponchio, F., Rizzo, F., Rubino, A.R., Scopigno, R., Sobra', G., 2018. A 3D-centered information system for the documentation of a complex restoration intervention. J. Cult. Herit., 29, 89-99. doi.org/10.1016/j.culher.2017.07.010.

Apollonio, F.I., Rizzo, F., Bertacchi, S., Dall'Osso, G., Corbelli, A., Grana, C., 2017. SACHER: Smart Architecture for Cultural Heritage in Emilia Romagna. Grana, C., Baraldi, L. (eds), Digital Libraries and Archives. IRCDL 2017. CCIS, 733. Springer, Cham, 142-156. doi.org/10.1007/978-3-319-681306_12.

Banfi, F., 2017. BIM Orientation: Grades of Generation and Information for Different Type of Analysis and Management Process. Int. Arch. Photogramm. Remote Sens. Spatial Inf. Sci., XLII-2/W5, 57-64. doi.org/10.5194/isprs-archives-XLII-2-W5$57-2017$.

Bertacchi, S., Al Jawarneh, I.M., Apollonio, F.I., Bertacchi, G., Cancilla, M., Foschini, L., Grana, C., Martuscelli, G., Montanari, R., 2018. SACHER Project: A Cloud Platform and Integrated Services for Cultural Heritage and for Restoration. Goodtechs '18 Proceedings of the 4th EAI International Conference on Smart Objects and Technologies for Social Good, 283-288. doi.org/10.1145/3284869.3284871.
Biagini, C., Capone, P., Donato, V., Facchini, M., 2016. Towards the BIM implementation for historical building restoration sites. Automation in Construction, 71(1), 74-86. doi.org/10.1016/j.autcon.2016.03.003.

Catmull, E., Clark, J., 1978. Recursively generated B-spline surfaces on arbitrary topological meshes. Computer-Aided Design, 10(6), 1978, 350-355.

Chiabrando, F., Donato, V., Lo Turco, M., Santagati, C., 2018. Cultural Heritage Documentation, Analysis and Management using Building Information Modelling: State of the Art and Perspectives. Ottaviano E., Pelliccio A., Gattulli, V. (eds), Mechatronics for Cultural Heritage and Civil Engineering. Intelligent Systems, Control and Automation: Science and Engineering, 92. Springer, Cham, 181-202.

Cipriani, L., Dresseno, A., Agostini, P., Fantini, F., 2018. Game engine to communicate and enhance the city and the territory: the pilot project "Chiuro, dal passato, il futuro" - Game engine per comunicare e valorizzare città e territorio: il progetto pilota "Chiuro, dal passato, il futuro". Salerno, R. (ed), Rappresentazione Materiale/Immateriale - Drawing as (in) tangible representation. $40^{\circ}$ Convegno Internazionale UID dei Docenti delle Discipline della Rappresentazione, Milano, 13-15 settembre 2018. Gangemi Editore International, Roma, 10351042.

Cipriani, L., Fantini, F., 2018. Integration of Pipelines and Open Issues in Heritage Digitisation. Remondino, F., Georgopoulos, A., González-Aguilera, D., Agrafiotis, P. (eds), Latest Developments in Reality-Based $3 D$ Surveying and Modelling. MDPI, Basel, CH, 171-191. doi.org/10.3390/books978-3-03842-685-1-8.

Cipriani, L., Fantini, F., Bertacchi, S., 2014a. Survey and representation of vaults and cupolas: An overview on some relevant Italian UNESCO sites. Thwaites, H., Kenderdine, S., Shaw, J. (eds), International Conference on Virtual Systems \& Multimedia (VSMM). Hong Kong, China, 50-57. doi.org/10.1109/VSMM.2014.7136682.

Cipriani, L., Fantini, F., Bertacchi, S., 2014b. 3D models mapping optimization through an integrated parameterization approach: cases studies from Ravenna. Int. Arch. Photogramm. Remote Sens. Spatial Inf. Sci., XL-5, 173-180. doi.org/10.5194/isprsarchives-XL-5-173-2014.

Cipriani, L., Fantini, F., Bertacchi , S., 2016. Understanding Ancient Design through Survey: Examples from Hadrian's Villa. SCIRES-IT, 6(2), 133-150. dx.doi.org/10.2423/i22394303v6n2p133.

Cipriani, L., Fantini, F., Bertacchi, S., 2017. The Geometric Enigma of Small Baths at Hadrian's Villa: Mixtilinear Plan Design and Complex Roofing Conception. Nexus Netw. J., 19(2), 427-453. doi.org/10.1007/s00004-017-0344-x.

De Rose, T., Kass, M., Truong, T., 1998. Subdivision surfaces in character animation. SIGGRAPH' 98 Proceedings of the 25th annual conference on Computer graphics and interactive techniques. ACM New York, New York, 85-94.

Dore, C., Murphy, M., 2017. Current state of the art Historic Building Information Modelling. Int. Arch. Photogramm. 
Remote Sens. Spatial Inf. Sci., XLII-2/W5, 185-192. doi.org/10.5194/isprs-archives-XLII-2-W5-185-2017.

Fernández-Palacios, B.J., Morabito, D., Remondino, F., 2017. Access to complex reality-based 3D models using virtual reality solutions. Journal of Cultural Heritage, 23, 40-48. doi.org/10.1016/j.culher.2016.09.003.

Gaiani, M., Apollonio, F.I., Ballabeni, M., Cipriani, L., Fallavollita, F., Fantini, F., Sun, Z., 2015. Strumenti per lo studio dei portici di Bologna: un approccio attraverso una collezione di modelli digitali. Bocchi, F., Smurra, R. (eds), Bologna's Porticos in the European Context. Luca Sossella editore, Bologna, 165-180.

Gaiani, M., Apollonio, F.I., Ballabeni, A., Remondino, F., 2017. Securing Color Fidelity in 3D Architectural Heritage Scenarios. Sensors, 17(11), 2437. doi.org/10.3390/s17112437.

García-León, J., Sánchez-Allegue, P., Peña-Velasco, C., Cipriani, L., Fantini, F., 2018. Interactive dissemination of the $3 \mathrm{D}$ model of a baroque altarpiece: a pipeline from digital survey to game engines. SCIRES-it, 8(2), 59-76. dx.doi.org/10.2423/i22394303v8n2p59.

Gonizzi Barsanti, S., Caruso, G., Micoli, L.L., Covarrubias Rodriguez, M., Guidi, G., 2015. 3D Visualization of Cultural Heritage Artefacts with Virtual Reality devices. Int. Arch. Photogramm. Remote Sens. Spatial Inf. Sci., XL-5/W7, 165172, doi.org/10.5194/isprsarchives-XL-5-W7-165-2015.

Ioannides, M., Fink, E., Brumana, R., Patias, P., Doulamis, A., Martins, J., Wallace, M. (eds), 2018. Digital Heritage. Progress in Cultural Heritage: Documentation, Preservation, and Protection. EuroMed 2018. 7th International Conference, EuroMed 2018, Nicosia, Cyprus, October 29 - November 3, 2018, Proceedings, Part II, Lecture Notes in Computer Science, 11197. Springer, Cham. doi.org/10.1007/978-3-030-01765-1.

Jakob, W., Tarini, M., Panozzo, D., Sorkine-Hornung, O., 2015. Instant field-aligned meshes. ACM Transactions on Graphics (TOG), 34(6), 189. doi.org/10.1145/2816795.2818078.

Logothetis, S., Delinasiou, A., and Stylianidis, E., 2015. Building Information Modelling for Cultural Heritage: a review. ISPRS Ann. Photogramm. Remote Sens. Spatial Inf. Sci., II5/W3, 177-183. doi.org/10.5194/isprsannals-II-5-W3-1772015 .

López, F.J., Lerones, P.M., Llamas, J., Gómez-García-Bermejo, J., Zalama, E., 2018. A Review of Heritage Building Information Modeling (H-BIM). Multimodal Technologies Interact., 2(2), 21. doi.org/10.3390/mti2020021.

Merlo, A., Fantini, F., 2012. I sistemi di ottimizzazione image based per la gestione dei modelli digitali 3D a scala urbana. Lavoratti, G. (ed), Il Castello di Pietrabuona. Materiali per la Ricerca. Edizioni ETS, Pisa, 159-165.

Merlo, A., Dalcò, L., Fantini, F., 2012. Game engine for Cultural Heritage: New opportunities in the relation between simplified models and database. 2012 18th International Conference on Virtual Systems and Multimedia. doi.org/10.1109/VSMM.2012.6365993.
Merlo, A., Sánchez Belenguer, C., Vendrell Vidal, E., Fantini, F., Aliperta, A., 2013. 3D Model Visualisation Enhancements in Real-Time Game Engines. Int. Arch. Photogramm. Remote Sens. Spatial Inf. Sci., XL-5/W1, 181-188. doi.org/10.5194/isprsarchives-XL-5-W1-181-2013.

MODO, 2019. Foundry MODO Software. Version 12.0v1. www.foundry.com (10 March 2019).

Muratov, O., Slynko, Y., Chernov, V., Lyubimtseva, M., Shamsuarov, A., Bucha, V., 2016. 3DCapture: 3D Reconstruction for a Smartphone. 2016 IEEE Conference on Computer Vision and Pattern Recognition Workshops (CVPRW). doi.org/10.1109/CVPRW.2016.116.

Napolitano, R.K., Scherer, G., Glisic, B., 2018. Virtual tours and informational modeling for conservation of cultural heritage sites. Journal of Cultural Heritage, 29, 123-129. doi.org/10.1016/j.culher.2017.08.007.

Nocerino, E., Lago, F., Morabito, D., Remondino, F., Porzi, L., Poiesi, F., Rota Bulo, S., Chippendale, P., Locher, A., Havlena, M., Van Gool, L., Eder, M., Fötschl, A., Hilsmann, A., Kausch, L., Eisert, P., 2017a. A Smartphone-Based 3D Pipeline for the Creative Industry - the REPLICATE EU Project. Int. Arch. Photogramm. Remote Sens. Spatial Inf. Sci., XLII-2/W3, 535541. doi.org/10.5194/isprs-archives-XLII-2-W3-535-2017.

Nocerino, E., Poiesi, F., Locher, A., Tefera, Y.T., Remondino, F., Chippendale, P., Van Gool, L., 2017b. 3D reconstruction with a collaborative approach based on smartphones and a cloud-based server. Int. Arch. Photogramm. Remote Sens. Spatial Inf. Sci., XLII-2/W8, 187-194. doi.org/10.5194/isprsarchives-XLII-2-W8-187-2017.

Opper, T. (ed), 2008. Hadrian: empire and conflict. The British Museum Press, London, UK.

PhotoScan, 2019. Agisoft PhotoScan Professional Edition Software. Version 1.4. www.agisoft.com (10 March 2019).

Pocobelli, D.P., Boehm, J., Bryan, P., Still, J., Grau-Bové, J., 2018. BIM for heritage science: a review. Heritage Science, 6, 30. doi.org/10.1186/s40494-018-0191-4.

Quattrini, R., Malinverni, E.S., Clini, P., Nespeca, R., Orlietti, E., 2015. From TLS to HBIM. High Quality SemanticallyAware 3D Modeling of Complex Architecture. Int. Arch. Photogramm. Remote Sens. Spatial Inf. Sci., XL-5/W4, 367374. doi.org/10.5194/isprsarchives-XL-5-W4-367-2015.

Remondino, F., Georgopoulos, A., González-Aguilera, D., Agrafiotis, P. (eds), 2018. Latest Developments in RealityBased 3D Surveying and Modelling. MDPI, Basel, CH, 171191. doi.org/10.3390/books978-3-03842-685-1-8.

Scopigno, R., Dellepiane, M., 2017. Integration and Analysis of Sampled Data: Visualization Approaches and Platforms. Masini, N., Soldovieri, F. (eds), Sensing the Past. Geotechnologies and the Environment, 16. Springer, Cham, 377-393. doi.org/10.1007/978-3-319-50518-3_18.

UNREAL, 2019. Unreal Engine Software. Version 4.4. www.unrealengine.com (10 March 2019). 